\title{
Changes in sensation after nerve injury or amputation: the role of central factors
}

\author{
S Braune, W Schady
}

\begin{abstract}
Dynamic changes in somatosensory cortical maps are known to occur in experimental animals subjected to peripheral nerve transection or amputation. To study the sensory effects of central nervous system adaptation to temporary or permanent loss of input from a part of the hand, multimodality quantitative sensory tests were carried out in 11 patients with complete traumatic division and repair of the median or ulnar nerves and in six patients who had undergone amputation of one or more digits. As expected, vibration, two point discrimination, and tactile thresholds were raised in the territory of the injured nerve in a graded fashion, sensitivity being poorest in the patients with the most recent injuries. Surprisingly, localisation was better in the tips than at the base of the hypoaesthetic fingers, suggesting a central attentional gradient. Stimulus-response curves conformed to a power function whose exponent was higher in denervated than in normal skin. Changes in psychophysical functions were also discernible in the intact hand. There was no hyperaesthesia in the territory of the nerve adjacent to the injured one or in the stump in the case of amputees. Central factors contribute to the sensory changes seen after nerve injury, but the functional effects of the cortical reorganisation that follows partial deafferentation are more subtle than a simple heightening of sensitivity in the surrounding skin.
\end{abstract}

(F Neurol Neurosurg Psychiatry 1993;56:393-399)

The body surface is represented somatotopically in the mammalian somatosensory cortex. It has been shown, however, that cortical maps in rodents and monkeys can change during adult life in response to deafferentation. Within weeks or months of upper limb nerve transection the region of cortex serving the area of denervated skin, which initially falls silent, is taken over by inputs from other parts of the hand (for a review see Wall').

There is a wealth of information on the sensory events that follow nerve injury and regeneration in humans. Much less is known about the relative contribution of peripheral and central factors to functional recovery of sensation. It is self evident that unless the skin is reinnervated it will remain anaesthetic. As nerve fibres grow back to the skin from the site of injury, possibly with some contribution from collateral sprouting, ${ }^{2}$ the patient's sensory experience will be determined by the number and type of axons that establish functional connections with cutaneous receptors, by changes in the encoding properties of regenerated fibres, and by the brain's response to the initial sensory deprivation and subsequent return of afferent activity.

If a similar reorganisation in cortical maps occurs in humans as in animals after partial deafferentation, information from newly reinnervated cutaneous receptors might not be processed normally because their original cortical representation had been "taken over" by inputs arising elsewhere. In addition, cutaneous sensibility in the area surrounding the anaesthetic skin might be altered by its increased representation in the somatosensory cortex. The principal aim of our study was to assess the functional sensory effects of central nervous system adaptation to temporary (nerve injury) or permanent (amputation) loss of input from a part of the hand.

\section{Materials and methods}

PATIENTS

Patients who had suffered a traumatic upper limb nerve transection or finger amputation and had been treated in the department of plastic surgery at Withington Hospital were approached for participation in this study. Their informed consent was obtained in accordance with the Declaration of Helsinki.

\section{Nerve injury}

We studied 11 patients (6 men) with 12 microsurgically repaired nerve injuries. Their mean age was 35 years (range 17-73 years). The median nerve was affected in six patients, the ulnar nerve in five, and in one case both nerves had been divided. All lesions were at the wrist, with the exception of one patient whose ulnar nerve had been damaged in the distal third of the forearm. The left side was affected in seven patients and the right in five, the damaged limb being the dominant one in half.

In nine patients the injury was caused by accidental cuts from glass, one was due to damage by industrial machinery, and one was self inflicted with a knife. Surgical exposure confirmed total transection of the nerve in question in all cases. Epineurial repair was carried out in nine instances and fascicular 
repair in three, performed within 24 hours of injury except for one patient whose nerve was not repaired until two months later. The median interval between nerve injury and testing for the study was 10 (5-66) months. Patients were divided into those whose injury was less than a year old ( 8 nerves; median $9 \cdot 3$ months) and those whose injury was more than a year old (4 nerves; median $17 \cdot 8$ months). None of them had received formal sensory rehabilitation.

\section{Amputation}

In addition, we studied six patients who had undergone amputation of one (4 cases) or two digits ( 2 cases). They were all male, with a mean age of 35 (17-53) years. Three of the six fingers tested had been completely amputated; in the other three the proximal phalanx remained. Machine accidents were responsible in four patients. In the two others surgery was performed electively, namely for removal of a lump in one and for a chronic pain syndrome after a crush injury in the other. The dominant hand was affected in four patients, the non-dominant hand in two. During the operation the surgeon had stretched the digital nerve endings and thermocoagulated the distal 1-2 cm to prevent neuroma formation. The median interval between amputation and testing was $7 \cdot 3(5 \cdot 6-58)$ months.

\section{Methods}

A history of the nerve injury and its consequences was obtained in accordance with a set protocol. The affected limb was examined in detail and the area of sensory deficit was carefully mapped. Additional information about the initial clinical picture, the degree of nerve division, the operative technique, and the postoperative course was gained from the patient's notes.

Multimodal quantitative sensory tests were undertaken with the patient comfortably seated and the tested hand resting on a sandbag. The right hand was always tested first. Three areas were defined and tested separately, corresponding in nerve injury patients to maximally affected, partly numb, and unaffected skin.

Area $A$-In patients with nerve injuries the area of maximal numbness consisted of the pulp of the index or the little finger, depending on whether the median or the ulnar nerve had been divided. For amputees area A was located on the stump.

Area $B$-In patients with nerve injuries the area of partial numbness tested was on the volar aspect of the proximal phalanx of the same finger as for area $A$ or, if the maximal sensory deficit extended to the base of the digit, on the thenar or hypothenar eminence. In amputees area $B$ was at the base of the affected finger or, if digital amputation was complete, on the thenar or hypothenar eminence.

Area $C$-For patients with nerve injuries the area of unaffected skin tested was on the pulp of the little finger for median nerve lesions and on the pulp of the index for ulnar nerve lesions. For amputees area $\mathrm{C}$ was always on the pulp of the little finger, as all amputated digits were in the territory of the median nerve.

In both groups of patients all tests were repeated at the same sites in the unaffected hand (areas CA, CB, and CC), so that each patient served as his or her own control. Some tests included additional locations, as described below.

\section{Thermal and pain thresholds}

Warmth, cold, heat pain, and cold pain thresholds were determined by the Marstock method. ${ }^{3}$ A Peltier thermode with a surface area of $12.5 \mathrm{~cm}^{2}$ was applied on the thenar or hypothenar eminence, depending on the affected nerve. A weight of $240 \mathrm{~g}$ was placed on the thermode to ensure good contact. The baseline temperature was set at $31^{\circ} \mathrm{C}$, which the subjects perceived as thermally indifferent. The stimulating surface was then warmed $1^{\circ} \mathrm{C}$ a second until the subjects first perceived warmth, when they pressed a switch, thus returning the thermode temperature to baseline. The procedure was repeated a minimum of four times with intervals of about 10 seconds between them. The thermode was then cooled and the same sequence was used to obtain a cold threshold.

Thermal pain thresholds were measured with the same equipment, using a rate of change of $2^{\circ} \mathrm{C} / \mathrm{s}$ for heat pain and $3^{\circ} \mathrm{C} / \mathrm{s}$ for cold pain. Subjects were instructed to press the switch when they felt the thermode to have become painfully hot or cold, depending on the direction of the current. Five values were usually obtained for each thermal threshold and the mean of the last three was calculated.

\section{Vibration thresholds}

A vibrameter (Somedic AB) was used to measure vibration thresholds in the pulp of the little and index fingers. The device delivers a sine wave at $100 \mathrm{~Hz}$ through a hand held probe applied with a constant force, which was monitored by the investigator. The amplitude of the sine wave was slowly increased until vibration was first perceived; it was then reduced to obtain the vibration disappearance threshold. The mean of three perception and disappearance thresholds was used as a measure of sensitivity to vibration at each testing site.

\section{Tactile thresholds}

Tactile thresholds were obtained with a set of Semmes-Weinstein monofilaments, a variant of von Frey hairs. They were recalibrated in our laboratory, the maximum force exerted being given in millinewtons $(0.06-230 \mathrm{mN})$. The filaments were applied perpendicularly to the skin in areas A, B, and C. The threshold was considered as the force required to obtain a correct response in four out of five trials.

\section{Stimulus-response curves}

The relation between subjective sensory magnitude and stimulus intensity was studied fur- 
ther by obtaining stimulus-response curves. ${ }^{4}$ When the tactile threshold in area A had been established seven supra threshold filaments spanning the remaining range of the set were selected. The middle filament was used as the reference. Pairs of stimuli were delivered by prodding the skin with the reference, followed about a second later by another filament randomly chosen from among the seven originally selected. The second stimulus could thus be weaker, stronger, or identical to the first. The subject was asked to rate on an open scale the intensity of the second stimulus in relation to the reference, which was arbitrarily rated as 10. Each filament was tested at least four times and the mean value was used to plot the subject's intensity rating against the stimulus force. The procedure was carried out in areas $\mathrm{A}$ and $\mathrm{B}$ and at corresponding sites in the unaffected hand (areas CA and CB).

\section{Two point discrimination}

Two point discrimination was measured by means of calipers with blunt points applied in a longitudinal direction. The threshold was considered to be the smallest distance between the points which the patient felt as two stimuli in two out of three trials.

\section{Locognosia}

The patient's ability to localise tactile stimuli was tested with the technique introduced by Noordenbos. ${ }^{5}$ Subjects were given red goggles to wear. While their eyes were closed the hand was touched briefly but firmly with a red felt-tip pen $1 \mathrm{~mm}$ in diameter at the tip. Having opened their eyes, but still wearing red goggles, subjects were unable to see the red dot on the skin. They were asked to mark with a black felt tip pen the spot where they thought they had been touched. The distance between the red and black marks was measured and the direction of the error was documented. The test was carried out on the distal, middle, and proximal phalanges of the index, ring, and little fingers (twice in the ring finger-namely, along its ulnar and median aspects) and on the thenar and hypothenar eminences of both hands.

\section{Data analysis}

Sensory thresholds were not normally distributed, and non-parametric statistics were thus used throughout. Comparisons were made between the median test values at the same site on affected and non-affected hands and between several locations on the same limb. The Mann-Whitney $U$ test was used for unpaired data and Wilcoxon's signed rank test for paired data, with the SPSS-X statistical package.

\section{Results}

PATIENTS WITH NERVE INJURY

Clinical state

All patients had regained some degree of feeling in the territory of the affected nerve. A Tinel sign could be evoked over the scar in seven patients. Only one patient had spontaneous shooting pain from the site of injury to the fingers supplied by the damaged nerve. Dysaethesia on gentle touch or spontaneous paraesthesia in the hypoaesthetic area, or both, was recorded in seven patients. Motor deficits in the affected hand ranged from MRC grades 2-3 in five cases to grades 3-4 in three cases and grades $4-5$ in four cases. With regard to autonomic function, one half of the patients reported higher sensitivity to cold, leading to stiffness, occasional pain, and a colder feeling than in the unaffected hand. Sweating was subjectively increased in the territory of the damaged nerve in two cases.

\section{Nerve conduction studies}

Orthodromic motor and sensory nerve conduction studies were performed in 11 of the 12 injured nerves under investigation. Motor action potentials were obtainable in all but one, but sensory potentials could be recorded in only three. By comparison with the values obtained in the contralateral unaffected nerves, the mean distal latency of the motor action potentials was delayed by a factor of $1 \cdot 82$, the mean distal and proximal amplitudes were reduced to $26 \%$ and $30 \%$, respectively, and the mean nerve conduction velocity in the forearm segment was slowed to $82 \%$. The mean distal latency of the three sensory action potentials obtainable was delayed by a factor of 1.4 , while the mean amplitudes were only $24 \%$ of the values on the contralateral side.

\section{Sensory thresholds}

In the patient group as a whole, thermal thresholds and pain sensitivity were not altered at the sites tested (the thenar eminence for median nerve injuries and the hypothenar area for ulnar lesions), which were hypoaesthetic for tactile stimuli. The median difference in thresholds between right and left hands was $<1^{\circ} \mathrm{C}$ for warmth, cold, and heat pain, and $1.6^{\circ} \mathrm{C}$ for cold pain. The subgroup of patients whose injury was less than 12 months old were hypersensitive to painful thermal stimuli on the affected side: the median difference with the healthy side was $-2 \cdot 1^{\circ} \mathrm{C}$ for heat pain (range $-4 \cdot 1$ to $\left.-1^{\circ} \mathrm{C} ; \mathrm{p}<0.05\right)$ and $-5.3^{\circ} \mathrm{C}$ for cold pain $\left(-6.6\right.$ to $\left.-3.3^{\circ} \mathrm{C} ; \mathrm{p}=0.05\right)$.

Vibration thresholds were higher in area $\mathrm{A}$ (the zone of maximal numbness) than at the corresponding site $\mathrm{CA}$ in the opposite hand (median $1.1 \mu \mathrm{m}$ in area $A$ and $0.57 \mu \mathrm{m}$ in area CA; $p=0.033$ ). Tactile sensitivity showed the greatest alteration. The median tactile thresholds at the fingertip (area A) and at the base of the finger (area B) were 18.6 and $2.2 \mathrm{mN}$, respectively, both of which were significantly higher than the median values at homologous sites $\mathrm{CA}$ and $\mathrm{CB}$ in the sound limb (table 1). The highest values were observed in patients whose nerve injuries were recent (table 2).

Two point discrimination was not recordable from area $A$ in seven patients and from area $B$ in four patients. In the remainder, 
Table 1 Comparison between the affected and the non-affected limb for tactile and vibration thresholds, two point discrimination and locognosia in 11 patients with 12 nerve injuries

\begin{tabular}{|c|c|c|c|c|c|}
\hline Modality & $\begin{array}{l}\text { Affected } \\
\text { site }\end{array}$ & $\begin{array}{l}\text { Median (range) } \\
\text { threshold }\end{array}$ & $\begin{array}{l}\text { Control } \\
\text { site }\end{array}$ & $\begin{array}{l}\text { Median (range) } \\
\text { threshold }\end{array}$ & p Value \\
\hline $\begin{array}{l}\text { Tactile threshold }(\mathrm{mN}) \\
\text { Vibration threshold }(\mu \mathrm{m}) \\
\text { Two point discrimination }(\mathrm{mm}) \\
\text { Locognosia }(\mathrm{mm})\end{array}$ & $\begin{array}{l}\text { Area A } \\
\text { Area B } \\
\text { Area C } \\
\text { Area A } \\
\text { Area C } \\
\text { Area A* } \\
\text { Area B } \\
\text { Area C } \\
\text { DP } \\
\text { MP } \\
\text { PP } \\
\text { T }\end{array}$ & $\begin{array}{l}18 \cdot 6(1.9-146) \\
2 \cdot 2(0.06-146) \\
0.06(0.06-0.54) \\
1 \cdot 1(0.08-29 \cdot 4) \\
0.47(0.04-5 \cdot 1) \\
17.0(10-25) \\
15.5(6-42) \\
5.5(2-13) \\
5.0(3-9) \\
9.5(4-29) \\
11.5(3-31) \\
8.0(6-13)\end{array}$ & $\begin{array}{l}\text { Area CA } \\
\text { Area CB } \\
\text { Area CC } \\
\text { Area CA } \\
\text { Area CC } \\
\text { Area CA } \\
\text { Area CB } \\
\text { Area CC } \\
\text { CDP } \\
\text { CMP } \\
\text { CPP } \\
\text { CT }\end{array}$ & $\begin{array}{l}0.06(0.06-1.9) \\
0.06(0.06-0.7) \\
0.3(0.06-0.54) \\
0.57(0 \cdot 17-5 \cdot 1) \\
0.31(0.15-9.0) \\
4.0(2-9) \\
7.5(4-14) \\
4.0(2-17) \\
4.0(1-10) \\
6.0(2-11) \\
5.0(0-12) \\
6.0(3-13)\end{array}$ & $\begin{array}{l}0.002 \\
0.011 \\
\text { NS } \\
0.033 \\
\text { NS } \\
0.043 \\
0.035 \\
\text { NS } \\
\text { NS } \\
0.032 \\
0.023 \\
\text { NS }\end{array}$ \\
\hline
\end{tabular}

$\mathrm{DP}=$ distal phalanges, $\mathrm{MP}=$ middle phalanges, $\mathrm{PP}=$ proximal phalanges, $\mathrm{T}=$ turnaround hypothena eminences. Not recordable in 7 patients.

†Not recordable in 4 patients.

median discrimination was significantly increased in sites A and B by comparison with their counterparts in the unaffected hand (table 1). For two point discrimination, as for vibration and tactile thresholds, the median right-left difference for area $\mathrm{C}$ was zero.

The ability to localise tactile stimuli (locognosia) was impaired in the middle and proximal phalanges of the fingers supplied by the injured nerve. The largest error in localisation was $31 \mathrm{~mm}$. Misreferrals tended to be in a longitudinal direction and did not extend to the cutaneous territory of a neighbouring nerve. There were no differences between the values obtained on the medial and lateral aspects of the ring finger. Surprisingly, locognosia was virtually normal in the tips of the fingers supplied by the injured nerve. The median difference between affected and unaffected sides at this location was $1 \mathrm{~mm}$, with a narrower range of values than at any of the other sites tested (fig 1). Misreferrals were of the same order in the two subgroups of patients for the distal and middle phalanges. For the proximal phalanx locognosia was better in those whose repairs had been carried out more than 12 months earlier (table 2 ).

\section{Stimulus-response curves}

The stimulus-response curves resulting from plotting the patient's subjective rating of the intensity of a range of tactile stimuli against stimulus force were best described as a power

Table 2 Differences in threshold between affected and unaffected limb for patients whose nerve injuries were less or more than a year old

\begin{tabular}{llcc}
\hline & & \multicolumn{2}{c}{ Median (range) difference in threshold } \\
\cline { 3 - 4 } Modality & Site & Injury & Injury \\
& compared & $<12$ months old & $>12$ months old \\
\hline Tactile threshold $(\mathrm{mN})$ & A-CA & $49 \cdot 9(1 \cdot 8-144)$ & $11 \cdot 3(1 \cdot 8-19)$ \\
& B-CB & $8 \cdot 9(0-147)$ & $1 \cdot 1(-0 \cdot 5-6)$ \\
Vibration threshold $(\mu \mathrm{m})$ & C-CC & $0(-0 \cdot 5-0)$ & $0(-0 \cdot 5-0 \cdot 6)$ \\
\multirow{2}{*}{ Two point discrimination $(\mathrm{mm})$} & A-CA & $3 \cdot 7(-0 \cdot 2-24)$ & $-0 \cdot 3(-1-3 \cdot 3)$ \\
& C-CC & $-0 \cdot 1(-3 \cdot 9-0 \cdot 5)$ & $0(-0 \cdot 6-0 \cdot 3)$ \\
\multirow{2}{*}{ Locognosia $(\mathrm{mm})$} & B-CB十 & $21 \cdot 5(21-22)$ & $10 \cdot 5(8-13)+2$ \\
& C-CC & $1(0-35)$ & $5(-1-21)+1$ \\
& DP-CDP & $0(-4-2)$ & $1(0-4)$ \\
& MP-CMP & $8 \cdot 5(-2-2)$ & $2(-1-4)$ \\
& PP-CPP & $10 \cdot 5(-9-26)$ & $8(3-8)$ \\
& T-CT & $2(-7-6)$ & $3(-2-8)$ \\
& &
\end{tabular}

$\mathrm{DP}=$ distal phalanges, $\mathrm{MP}=$ middle phalanges, $\mathrm{PP}=$ proximal phalanges, $\mathrm{T}=$ thenar and hypothenar eminences.

$\star$ Not recordable in 5 patients.

tNot recordable in 3 patients. function conforming to a straight line on log$\log$ coordinates (fig 2). The slope of this line (the exponent of the power function) was significantly steeper in the pulp of the fingers supplied by the injured nerve (area $A$ ) than at the same location in the other hand (area CA) (median $0.68 v 0.38 ; p=0.003$ ). For area $B$ the difference in slopes between injured and healthy hands was less but still significant $(0.39 v 0.27 ; \mathrm{p}=0.045)$.

The slopes of the stimulus-response curves at the tip and base of the fingers in the normal hand also differed, being significantly steeper at CA $(0.38)$ than CB $(0.27 ; p=$ $0.005)$. The median slopes tended to be lower in the group of patients whose injuries were more than 12 months old than those under 12 months (A, $0.39 v 0.74) ; \mathrm{B}, 0.40 v$ 0.62 ; CA, $0.28 v 0.44$; CB, $0.26 v 0.34$ ), but these differences were not statistically significant. In a group of seven age matched controls there were no differences between the slopes of stimulus-response curves at the same locations (median slopes 0.41 at A, 0.40 at $\mathrm{CA}, 0.44$ at $\mathrm{B}$, and 0.37 at $\mathrm{CB}$ ).

PATIENTS WITH AMPUTATED FINGERS

Sensitivity in the stump (A) or the adjacent skin (B) was not significantly different from sensitivity in the corresponding sites in the other hand (CA, CB), though small numbers made meaningful statistical analysis difficult. Acuity for any of these tests was not improved in the skin of the stump. Indeed, thresholds tended to be somewhat higher in the affected hand (median tactile thresholds $0.62 \mathrm{mN}$ in $\mathrm{A} v 0.06 \mathrm{mN}$ in $\mathrm{CA}$ and $0.6 \mathrm{mN}$ in $\mathrm{B} v 0.3 \mathrm{mN}$ in $\mathrm{CB}$; median two point discrimination $10.5 \mathrm{~mm}$ in $\mathrm{A} v 4.5 \mathrm{~mm}$ in $\mathrm{CA}$ and $9.0 \mathrm{~mm}$ in $B \quad v 7.0 \mathrm{~mm}$ in $\mathrm{CB}$ ). Locognosia was moderately impaired in the palm a few centimetres proximal to the stump (location B; median $7.5 \mathrm{~mm} v 3 \mathrm{~mm}$ in the intact limb). Vibration, thermal, and pain thresholds were similar in both hands.

The slopes of the stimulus-response curves obtained in the same way as for patients with nerve injuries did not show any side to side differences. The slopes in areas A $(0.49)$ and CA $(0.48)$ were steeper than those in $B$ $(0.32)$ and $C B(0.30)$, but these differences did not reach statistical significance. 
$\mathbf{m N}$

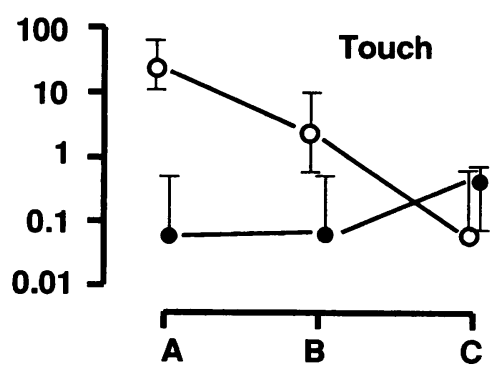

$\mathbf{m m}$

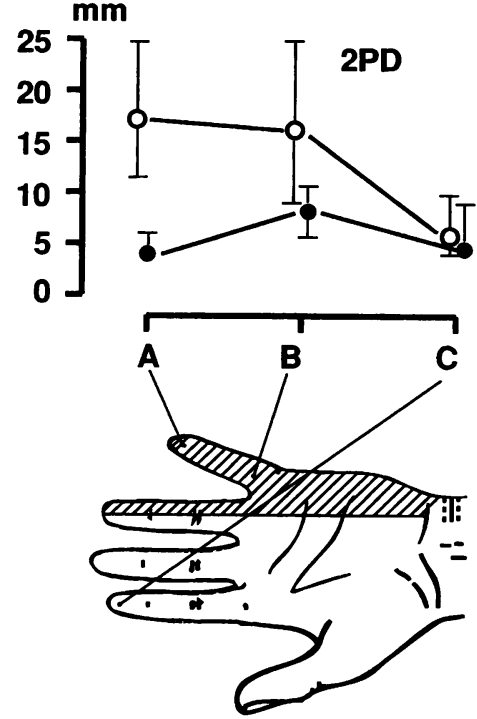

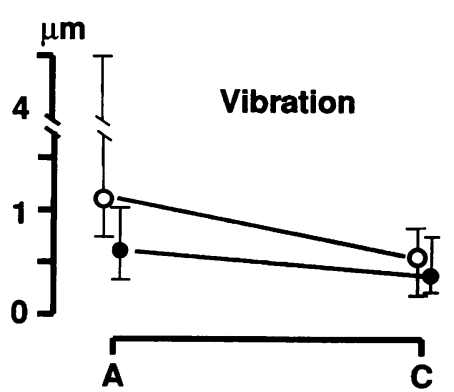
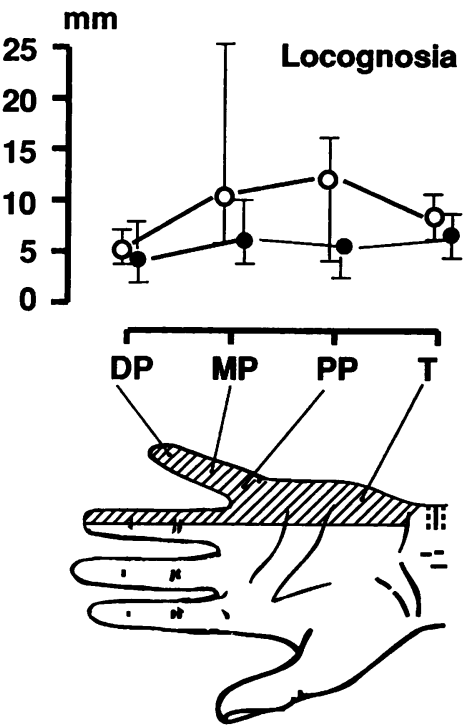

Figure 1 Median thresholds and quartiles for touch, vibration, two point discrimination, and locognosia at different sites in the hand after peripheral nerve regeneration.

Figure 2 Stimulusresponse function in a patient with a right ulnar nerve lesion. The force of the tactile stimulus is plotted against the subject's mean rating of intensity in several trials. Circles correspond to values obtained from the pulp of the righ little finger (site A) and crosses correspond to values from the intact left little finger (site $C A$ ).

\section{Discussion}

We studied 11 patients with 12 complete, microsurgically repaired median or ulnar nerve transections. The interval between nerve injury and testing of sensibility averaged 10 months, so it can be assumed that some regeneration had occurred. To observe the effect of permanent deprivation of sensory input we also studied six patients who had undergone amputation of one or more fingers. Standard methods were used to assess sensibility. ${ }^{67}$ All techniques of quantitative sensory testing have the inherent problem of

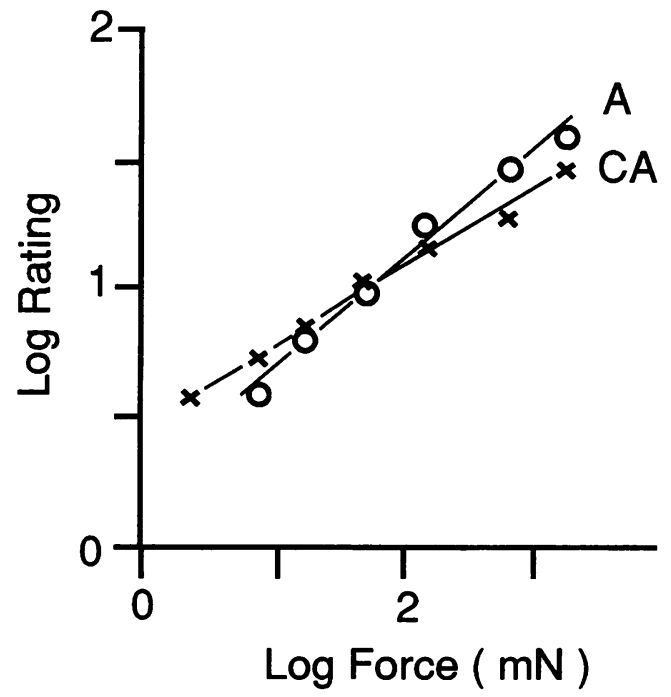

intrasubject and intersubject variability, so it was reassuring to find in our patients that for healthy skin the median right-left difference in touch, two point discrimination, and vibration thresholds was exactly zero. There was thus no effect on these results of dominance or order of testing.

Some of the findings in area A (area of maximal numbness) and area $B$ (partial numbness) in our patients with nerve injuries can be ascribed to peripheral factors. As expected, touch was impaired in areas $A$ and B in a graded fashion. Similar proximo-distal gradation in mechanical thresholds after nerve suture has been noted by many authors. ${ }^{8-10}$ It is of interest that sensitivity was better in the group of patients whose lesions were over a year old, indicating ongoing regeneration of nerve fibres and establishment of adequate connections with cutaneous receptors. ${ }^{11-13}$

Vibration thresholds were also raised in area $\mathrm{A}$, though less so than tactile thresholds, probably because of propagation of the stimulus outside the hypoaesthetic zone. Pacinian corpuscles, which are responsible for encoding high frequency vibration, are known to have very low firing thresholds and large receptive fields. ${ }^{14}$ Deep afferents (for instance, those in the interossei in the case of median nerve lesions) may also have been activated by the vibratory stimulus. It is unlikely that reinnervated cutaneous Pacinian corpuscles contributed much to vibration sensitivity in our patients, as few if any units of these corpuscles make successful connections with receptors of this class, ${ }^{15}$ though there may be some cross reinnervation of Pacinian receptors by sensory axons previously specialised differently. ${ }^{16}$ In a recently published case of forearm amputation and replantation, where propagation of the stimulus to the intact skin cannot have occurred, vibration sensitivity was the only submodality to be totally absent three and a half years after the accident. ${ }^{17}$

Thermal thresholds were not altered in our patients, perhaps because they were tested in the palm of the hand 5-66 months after nerve repair, by which time large numbers of regenerating unmyelinated and small myelinated fibres should have covered the short distance between the site of injury and the thenar or hypothenar eminence. ${ }^{18}$ However, hyperalgesia persisted in these areas during the first 12 months, a phenomenon described by Head and Sherren in $1905^{19}$ and subsequently confirmed by others. ${ }^{8021}$ It has variously been thought to be due to central release from inhibitory influences, ${ }^{22}$ lowered thresholds in regenerating polymodal nociceptors, ${ }^{18}$ or ectopic discharges generated in the injured nerve. ${ }^{23}$

Two point discrimination is one of the oldest tests of cutaneous sensibility. It has the drawback of being static, whereas tactile recognition usually involves exploration by the moving finger. Nevertheless, defective two point discrimination is a useful pointer to imperfect reinnervation at a time when ordinary threshold tests may have normal- 
ised, ${ }^{1924-26}$ in our patients with nerve repair. It was unrecordable in over half (understandably so since most injuries were relatively recent) and was impaired at sites $A$ and $B$ in the remainder. We also found somewhat defective discrimination and touch in the stump of patients who had undergone amputation of a finger. This is probably explained by distortion of the normal anatomical relationships between the skin flaps used to cover the stump, though central factors may also be involved.

Localisation of touch (locognosia) is a more functional task than threshold tests and may be a better predictor of outcome after nerve injury than two point discrimination. ${ }^{27}$ Tactile stimuli are misreferred long after nerve fibre regeneration has occurred, possibly because of misdirection of outgrowing axons, with persisting abnormalities in the topographic organisation of the central nervous system. ${ }^{28-31}$ It was thus unexpected to find normal locognosia in the fingertips of our nerve injured patients, although elsewhere in the finger localisation was significantly impaired. Dyck et al reported normal primary localisation when testing the fingers of patients several years after median nerve injury, but the perceptual territory was increased. ${ }^{32}$ Other authors have not tested several areas of skin systematically with punctate stimuli. The fact that in our patients the fingertips were the first to recover normal localisational capacity, when they should be the least endowed with reinnervated mechanoreceptors, indicates that central factors are at play. For the purpose of localising a tactile stimulus, preferential attention is paid to information from the fingertips, however scanty, because of its greater relevance in active touch. It has been shown that in the fingertips of healthy subjects input from a single mechanoreceptive unit may suffice for accurate point localisation. ${ }^{33}$

We did not observe any misreferral of tactile sensations from the healthy skin to the cutaneous territory of the injured nerve, for instance in the ring finger. This might have been expected if collateral sprouting of nerve fibres from adjacent normally innervated skin had occurred. However, such sprouting is restricted in experimental animals to high threshold afferents, which mediate perception of pain and temperature. ${ }^{103435}$ Our thermal stimulator could be used only in the palm and was too large to carry out thermal localisation tests.

The subject's rating of the intensity of various tactile stimuli is a psychophysical function that depends on the recruitment of sensory units but probably also on central factors. Our findings indicate that temporary or permanent deprivation of peripheral input causes the power function to become steeper-that is, sensory magnitude grows more rapidly with increasing stimulus force: stimulus-response curves in our patients were steeper in the hypoaesthetic fingers (areas A and B) than in the healthy skin of the opposite hand (areas CA and CB), and they tend- ed to be steeper in the first 12 months after injury than later on, when presumably innervation was richer. Similar findings were reported by Franzen and Lindblom. ${ }^{36}$ It is as if the central nervous system were trying to compensate for the loss of peripheral input by assigning higher intensity ratings to suprathreshold stimuli. Our normal controls showed no difference in the slope of the stimulus-response function between tip and base of the fingers.

Another finding that cannot be explained on a peripheral basis is the steeper slope of the psychophysical intensity function in the fingertip than the finger base in the normal hand of our nerve injured patients. In addition, our data in amputees showed a trend towards steeper slopes both in the stump and at the corresponding contralateral location, in the absence of tactile threshold changes. This may indicate a general resetting of the responsiveness of the brain to suprathreshold tactile cutaneous stimuli, even those from the other side of the body, when there is loss of input from one finger.

Nevertheless, the brain does not respond by heightening the sensitivity of the skin to just noticeable stimuli in the territory of the nerve adjacent to the injured one or in the stump in amputees. Multimodality thresholds in these areas were not significantly different from those at corresponding sites in the intact limb. This is in contrast with Haber's finding of improved tactile acuity in stumps of above elbow amputations. ${ }^{37}$ The different amount of amputated tissue may account for the difference between Haber's and our results.

In conclusion, our findings support the role of central factors in certain judgments of intensity and localisation of a cutaneous tactile stimulus after sensory deprivation. The cortical reorganisation that follows digit amputation or nerve section in monkeys ${ }^{31} 38$ might be anticipated to cause hypersensitivity in the adjacent skin, owing to the improved "grain" of its somatosensory representation. This is probably too simplistic a view of the central nervous system's adaptation to loss of afferent input. Subtle changes taking place at cortical or subcortical level may be aimed at making the best use of the sparse or distorted input from the partially deafferented area of skin. Dynamic changes in the central nervous system after nerve repair and regeneration may form the basis for successful sensory rehabilitation in such patients. ${ }^{39}$

This study was supported by a grant from the Hanns Seide Stiftung. We thank Mr S Watson for allowing us to study patients under his care and Dr R Schmidt and Professor H E Torebjörk for help in the design of the study protocol.

Wall JT. Variable organization in cortical maps of the skin as an indication of the lifelong adaptive capacities of cir-
cuits in the mammalian brain. TINS 1988;11:549-57.

2 Inbal R, Rousso M, Ashur H, Wall PD, Devor M Collateral sprouting in skin and sensory recovery after nerve injury in man Pain 1988:28:141-54

3 Fruhstorfer H, Lindblom U, Schmidt WG. Method fo quantitative estimation of thermal thresholds in patients. F Neurol Neurosurg Psychiatry 1976;39:1071-5.

4 Stevens SS. Sensory power functions and neural events In: Loewenstein WR, ed. Handbook of sensory physiolog Vol 1. Berlin: Springer, 1971: 226-42. 
5 Noordenbos $W$. The sensory stimulus and the verbalization of the response: the pain problem. In: Somjen JJ, ed. Neurophysiology studied in man. Amsterdam Excerpta Medica, 1972:207-14.

6 Lindblom U. Quantitative testing of sensibility including pain. In: Stalberg E, Young RR, eds. Clinical neurophysiology London: Butterworth, 1981:168-90.

7 Mitchell S, Schady W. Somatic sensation in the elderly. In: Thomas PK, ed. Peripheral nerve changes in the elderly. Chichester: Wiley, 1988:157-64.

8 Trotter W, Davies HM. Experimental studies in the innerTrotter W, Davies HM. Experimental studies in
vation of the skin. $\mathcal{F}$ Physiol 1909;38:134-246.

9 Seddon HJ. Surgical disorders of the peripheral nerves. 2nd ed. Edinburgh: Churchill Livingstone, 1975.

10 Kingery WS, Vallin JA. The development of chronic mechanical hyperalgesia, autotomy and collateral sprouting following sciatic nerve section in rat. Pain 1989;38:321-32.

11 Burgess PR, Horch KW. Specific regeneration of cutaneous fibers in the cat. $\mathcal{F}$ Neurophysiol 1973;36:101-14.

12 Horch K. Guidance of regrowing sensory axons after cutaneous nerve lesions in the cat. $\mathcal{f}$ Neurophysio 1979;42:1437-49.

13 Terzis J K, Dykes R W. Reinnervation of glabrous skin in baboons: properties of cutaneous mechanoreceptors subsequent to nerve transection. $f$ Neurophysiol subsequent to

14 Johansson R S. Tactile sensibility in the human hand: receptive field characteristics of mechanoreceptive units
in the glabrous skin area. $\mathcal{F}$ Physiol $1978 ; 281: 101-23$.

15 Mackel R, Kunesch E, Waldhor F, Struppler A Reinnervation of mechanoreceptors in the human glabrous skin following peripheral nerve repair. Brain Res 1983;268:49-65

16 Schiff J, Loewenstein W R. Development of a receptor on a foreign nerve fiber in a pacinian corpuscle. Science 1972;177:712-5.

17 Krarup C, Upton J, Creager M A. Nerve regeneration and reinnervation after limb amputation and replantation: clinical and physiological findings. Muscle Nerve 1990;13:291-304.

18 Shea V K, Perl E R. Regeneration of cutaneous afferent unmyelinated (C) fibers after transection. F Neurophysiol $1985 ; 54: 502-12$

$19 \mathrm{Head} \mathrm{H}$, Sherren J. The consequences of injury to the peripheral nerves in man. Brain 1905;28:116-338.

20 Sunderland $S$, Kelly $M$. The painful sequelae of injuries to peripheral nerves. Aust $N Z \mathcal{F}$ Surg 1948;18:75-118.

21 Denny-Brown D. The release of deep pain by nerve injury. Brain 1965;88:725-38.

22 Boring E G. Cutaneous sensation after nerve division. Qf Exp Physiol 1916;10:1-95.

23 Ochoa J. Pain in local nerve lesions. In: Culp W J, Ochoa $\mathrm{J}$, eds. Abnormal nerves and muscles as impulse generators. New York and Oxford: Oxford University Press, 1982: 568-87.
24 Onne L Recovery of sensibility and sudomotor activity in the hand after nerve suture. Acta Chir Scand 1962;300(suppl):1-69.

25 Kankaanpaa U, Bakalim G. Peripheral nerve injuries of the upper extremity. Sensory return of 137 neurorrhaphies. Acta Orthop Scand 1976;47:41-5.

26 Wynn Parry C B, Salter M. Sensory reeducation after median nerve lesions. Hand 1976;8:250-7.

27 Marsh D. The validation of measures of outcome following suture of divided peripheral nerves supplying the hand. 7 Hand Surg $[B r]$ 1990;15:25-34.

28 Hawkins G L. Faulty sensory localization in nerve regeneration. An index of functional recovery following sution. 7 An index of function $1948 ; 5: 11-8$.

29 Hallin $R$ G, Wiesenfeld Z, Lindblom U. Neurophysiological studies on patients with sutured median nerves: faulty sensory localization after nerve regeneration and its physiological correlates. Exp Neurol 1981;73:90-106

30 Mackel R, Brink E E, Wittkowsky G. Properties of cutaneous mechanosensitive afferents during the early stages of regeneration in man. Brain Res 1985;329: $49-69$.

31 Wall J T, Kaas J H, Sur M, Nelson R J, Felleman D J, Merzenich $M \quad M$. Functional reorganization in somatosensory cortical areas $3 \mathrm{~b}$ and 1 of adult monkeys after median nerve repair: possible relationships to sensory recovery in humans. I Neuroscience 1986;6: sensory

32 Dyck $\mathrm{P}$ J, Lambert E H, Wood M B, Linscheid R L. Assessment of nerve regeneration and adaptation after median nerve reconnection and digital

33 Schady W, Torebjork H E, Ochoa J L. Cerebral localization function from the input of single mechanoreceptive units in man. Acta Physiol Scand 1983;119:277-85.

34 Devor M, Schonfeld D, Seltzer Z, Wall P D. Two modes of cutaneous reinnervation following peripheral nerve injury. F Comp Neur 1979;185:211-20

35 Brenan A. Collateral reinnervation of skin by $\mathrm{C}$ fibers following nerve injury in the rat. Brain Res 1986; 385:152-5.

36 Franzen $\mathrm{O}$, Lindblom $U$. Tactile intensity functions in patients with sutured peripheral nerve. In: Zotterman,
ed. Sensory functions of the skin in primates. Oxford: ed. Sensory functions of

37 Haber W B. Effects of loss of limb on sensory function. 7 Psychol 1955;40:115-23

38 Merzenich M M, Nelson R J, Stryker M P, Cynader M S, Schoppmann A, Zook J M. Somatosensory cortical map changes following digit amputation in adult monkeys. f Comp Neurol 1984;224:591-605.

39 Dellon A L, Curtis R M, Egerton M T. Reeducation of sensation in the hand after nerve injury and repair. Plastic Reconstr Surg 1974;53:297-305. 